\title{
The Knowledge Frame System based on Principles of Topological Functioning Model
}

\author{
Vladislavs Nazaruks \\ Riga Technical University, Latvia
}

\begin{abstract}
Understanding of domain phenomena and their interrelations is necessary for successful software development. The knowledge frame system based on principles of Topological Functioning Modelling (TFM) can be used for this purpose at the Computation Independent level within Model Driven Development. Research on knowledge formats showed that inferring in the closed world paradigm and similarity to the object-oriented paradigm made frames an attractive candidate to the knowledge representation format. Frames can hold information necessary for generation of the TFM. The knowledge system based on the principles of the TFM does not allow inferring ambiguous facts and leads to the more complete discovery of knowledge.
\end{abstract}

Keywords - Knowledge base, knowledge frame, model driven development, model transformation, topological functioning model.

\section{INTRODUCTION}

Suitability of information systems to the business domain operation is one of the main issues in software development. Appearance of Model Driven Architecture (MDA) [1] in 2001 can be considered as the first step towards solving this issue. MDA can be defined as "an approach to system development and interoperability that uses models to express and direct the course of understanding, requirements elicitation, design, construction, deployment, operation, maintenance, and modification" [2]. The key principle of MDA is "separation of concerns" in specifications. The principle of separation of concerns has been used in programming languages since the 1970s, but applied to the specifications only in 2001. The MDA separates the following concerns: computation independent, platform independent and platform specific. Each concern is represented in corresponding models, namely a computation independent model (CIM), a platform independent model (PIM) and a platform specific model (PSM).

The present research focuses on the CIM that can be represented as an unstructured text, structured text, or semiformal (or even informal) graphical representations. The CIM describes knowledge about the analysed domain, business rules and processes used within it, data vocabulary, and even system and software requirements [1]. The CIM can be represented by means of BPMN [3], Data Flow Diagrams [4], UML diagrams (e.g., use case and activity diagrams), user stories, business rules [5], etc. The CIM may be relatively separated into three related to each other sub-models, namely CIM - Knowledge Model, CIM - Business Model and CIM Business Requirements for the System [6]. The CIMBusiness Model depends on CIM - Knowledge Model and is a source for CIM-Business Requirements for the System (Fig. 1).

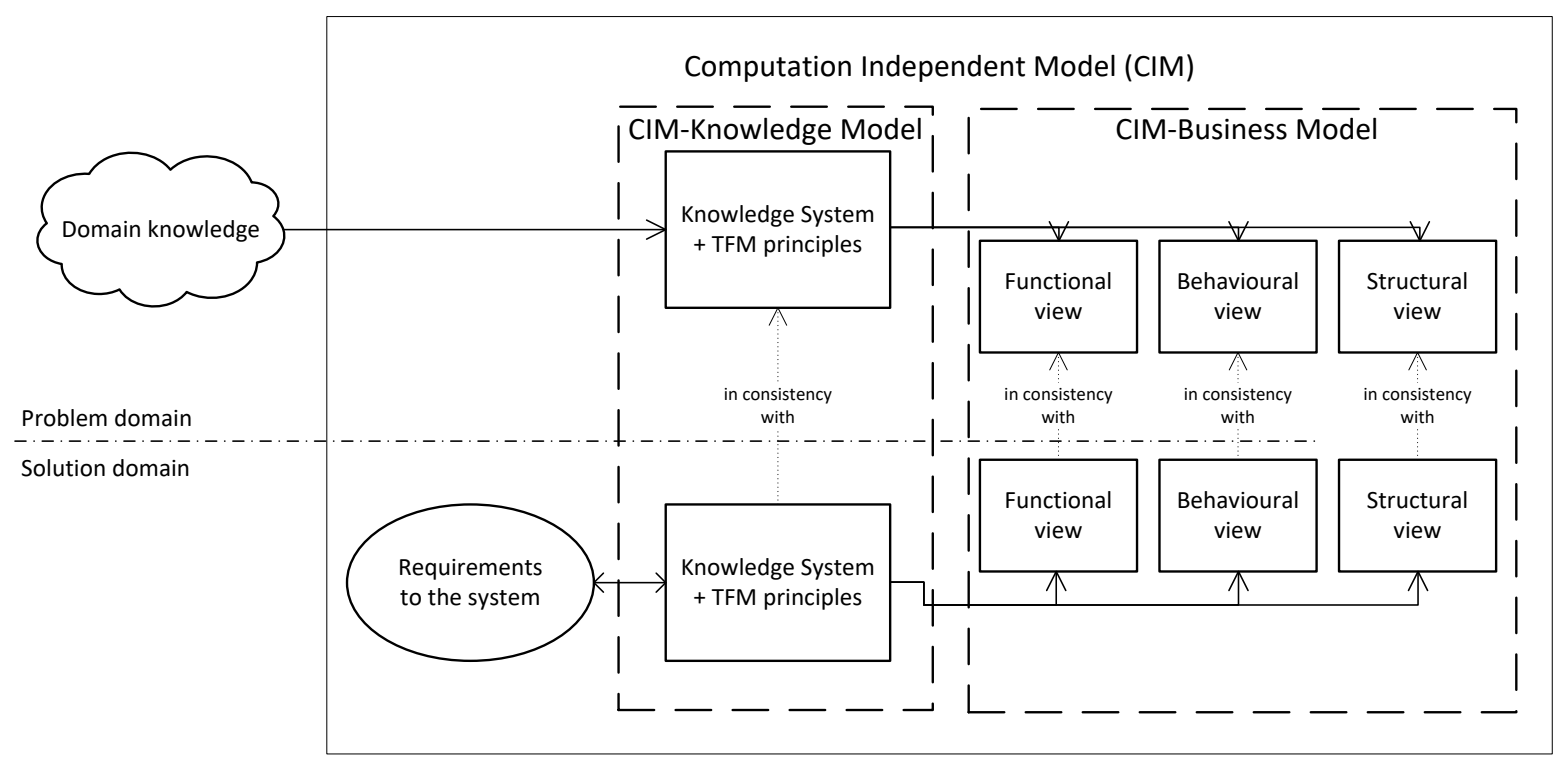

Fig. 1. The view on knowledge base at the computation independent level 
Using informal or semi-formal knowledge representation formats makes automated processing and inferring quite difficult or even impossible. Therefore, the question is how to represent domain knowledge to have enough facts and rules on the domain to automate knowledge processing for model-tomodel transformations within the CIM.

The hypothesis is that a knowledge base can serve as a root for model-to-model transformation when using topological functioning modelling (TFM) as a CIM-Business Model (such use is described in [6]). However, this base must implement the main principles of the TFM in some way. The knowledge kept in the base must be transferred to models of functional, behavioural and structural views (Fig. 1).

The goal of the current research is to check this hypothesis for the generation of the model of the functional view, i.e., of the TFM. The tasks performed here are the following: 1) to understand what knowledge representation format can be used for this knowledge base (Section II), to develop an initial version of the knowledge base for domain ontology representation (Section III), and to check this base on the example (Section IV).

The paper is a revised and extended version of [7] focused on a more exhaustive explanation of a decision on choosing the knowledge representation format and demonstration of manually filled in and generated information in frame instances.

Presence of the knowledge base in software development process should shift the focus of problem domain analysis from the separate investigation of dynamic and structural aspects of the system to the deep understanding of domain phenomena and their interrelations.

\section{BACKGROUND AND RELATED WORK}

\section{A. Knowledge System Worlds}

There are different formats for knowledge representation in computer science. They are knowledge frame networks, ontology, concept networks, product rules, logics of different orders, and even artificial natural languages (e.g., Esperanto, Conlang, Lingvata as stated in [8]).

The diversity of formats is related to format limitations that are caused by two of the most fundamental problems in the field of expert systems, namely knowledge acquisition and representation [9] and search [9], [10].

Two most widely-used ontology modelling paradigms are ontology implemented in Web Ontology Language (OWL) and knowledge frames [11]. Both paradigms have many similar constructs; however, major differences are in semantics of these constructs and the way how they are used [12]:

- Unique name assumption - OWL ontology does not support the assumption of the unique names; two objects with different names may mean the same. In frames, two objects with different names are assumed to be different;
- Closed World and Open World assumption - the same strictness is in permissions. In frames, everything is prohibited by default, contrary to OWL;

- Single or Multiple models - the frame ontology can only contain instances that satisfy each of the assertions, it is a single model. In turn, OWL ontology may have many models of all possible interpretations if they satisfy each of the assertions;

- Properties belonging - in frames, slots must be explicitly attached to classes, while in OWL they may belong to any class if it is not specified otherwise;

- Belonging to a class - in OWL it is possible to infer which classes are subclasses of the defined class. There is no equivalent feature in frames;

- Treatment of multiple domains and ranges - in frames it is a union, while in OWL it is an intersection;

- Default reasoning - the key strength of frames is not available in OWL.

Similarity to the object-oriented modelling paradigm and inferring in the closed world paradigm make frames an attractive candidate to the knowledge representation format of the CIM-Knowledge Model. Therefore, it is worth understanding its applications nowadays.

\section{B. Related Work on Knowledge Frame Application}

There are several questions that have been stated in [13] related to knowledge entering into the knowledge base of frames, declarative and procedural knowledge representation and corresponding limitations, as well as integration with other knowledge representation formats.

The widely used way of entering knowledge into the frame knowledge base is manual, i.e., a knowledge engineer enters facts and assertions about the domain based on results of interviews with domain experts and other information about the domain [14]-[17]. Only in case of text analysers automated entering is applied, but the amount of human participation in this process is not clear [18]-[21].

Frame-based representation of declarative and procedural knowledge has a wide application, but the tendency of the last decade was health care and biomedicine (mostly for ontologies of terms) [14], [16], forecasting [16], [22], text/natural language processing [10], [16], [18]-[20], [23][29], and structural modelling for intellectual information systems [30].

Limitations mentioned by authors are inadequate representation of knowledge [23], greater expressiveness that can lead pure ontologies to the loss of information in case of transformation into them [16], [17], [25], necessity to work with the completely known characteristics and static knowledge domain [18], representation of the procedural knowledge as a programming code inside frames [18], and the fact that complex structures can decrease the performance of the system inference and execution [15], [19].

Integration with other knowledge representation systems is possible, e.g., with product rules and business constraints [31], OWL [17], [21], [31], fuzzy logic [26], and modal logic [29]. 
The overview of related research has shown that frame systems are in use, and optimistic attempts to adapt this knowledge representation format to new technologies occur. It opens a possibility for integrating frame-based knowledge systems with already existing ontologies and other knowledge representation techniques.

\section{KNOWLEDGE FRAME SYSTEM FOR DOMAIN ONTOLOGY REPRESENTATION}

\section{A. Topological Functioning Model}

The TFM is a formal model that describes the functioning of a system. Its fundamentals are published in [32]. The TFM can be specified as a topological space $(X, \Theta)$, where $X$ is a finite set of functional features of the system under consideration, and $\Theta$ is a topology on $X$. A functional feature is "a characteristic of the system (in its general sense) that is designed [for] and necessary to achieve some system goal" [33]. It can be specified by a unique 7-ple (1), where:

\section{$\langle A, \boldsymbol{R}, \boldsymbol{O}$, PrCond, PostCond, Pr, Ex $\rangle$}

- $A$ is an action linked with an object;

- $\quad \boldsymbol{R}$ is a result (results) of the action $A$;

- $\boldsymbol{O}$ is an object (objects) that gets the result of the action or an object (objects) that is used in this action;

- PrCond is a set of preconditions or atomic business rules;

- PostCond is a set of postconditions or atomic business rules;

- $\boldsymbol{P r}$ is a set of responsible entities (systems and/or subsystems) that provide or suggest an action with a set of certain objects;

- $\boldsymbol{E} \boldsymbol{x}$ is a set of responsible entities (systems or subsystems) that enact a concrete action [33], [34].

A TFM is valid when it satisfies topological and functioning properties [33]. The topological properties are: connectedness, neighbourhood, closure and continuous mapping. The functioning properties are: cause-and-effect relations, cycle structure, inputs and outputs.

The cycle structure is very important for validation of the TFM, it represents a system feedback. As mentioned in [30], in the system the feedback is a strategy that allows the system to compensate not waited interferences and perform selforganisation, as well as to avoid return to such an organisation form that does not satisfy criteria of functionality. The system implements the feedback in two ways: part of object outputs is returned to the object inputs, or an object takes information that provides the implementation of the feedback from its outputs.

By now validation of these properties may be automated only against the metamodel. The possibility of semantic validation of the TFM using execution model simulation is discussed in [35], where decision making is based on results presented in [36], and does require human participation.
In the present research, three approaches for complex system modelling are considered, namely TFM4MDA, TopUML and IDM.

The Topological Functioning Modelling for Model Driven Architecture (TFM4MDA) approach defined in [37] is intended for problem domain analysis and modelling in the context of MDA. It makes possible to use a formal TFM as a Computation Independent Model (CIM - Business Model).

The TopUML approach proposed in [38] combines TFM and its formalism with elements and diagrams of the TopUML modelling language, which is a specially developed profile of the Unified Modelling Language (UML). The TopUML modelling method "covers modelling and specification of systems in computation independent and platform independent viewpoints" [38].

The Integrated Domain Modelling (IDM) approach is proposed in [39]; the goal of this approach is "to provide an efficient way to acquire a domain model based on declarative and procedural domain knowledge". The approach "suggests using common system analysis and artificial intelligence practices to capture the domain knowledge and then transform these into a corresponding domain model" [39].

\section{B. Metamodels of the Topological Functioning Model}

There are three TFM metamodels, each developed within a concrete TFM application: TFM4MDA [40], [41], TopUML [38], [42] and IDM approach [39], [43].

The analysis of metamodels showed the following common elements: a topological functioning model, a functional feature, a cycle, an actor, a logical relationship, and a topological relationship, as well as two enumerations "Subordination" for functional feature subordination within the system and "LogicalOperation" for specification of logical operation on the set of topological relationships.

Other elements are specific for each approach. In case of TFM4MDA, they are required for transformation from TFM to use case specifications (an actor role, a business actor, a business worker, a functional requirement, and an enumeration "Benefit"). In case of TopUML, they are used for transformation to TopUML diagrams (a result of the action, a class, a state, a condition, and a topological operation). In case of IDM approach, the TFM is a target of the transformation; thus, the metamodel contains only elements necessary to TFM construction.

Considering these elements from problem and solution domain viewpoints, it can be concluded that several elements belong to the both problem and solution domains, and can be used in models at the corresponding levels. These elements are a topological functioning model, a functional feature, a functional feature set, a cycle, a correspondence [of the functional feature and functional requirement), a user role, enumerations "Subordination" and "LogicalOperation", a logical relationship, and a topological relationship. Other elements discussed belong to the solution domain. 


\section{Refinement of TFM Element Definitions}

The core elements of the TFM are a functional feature and a cause-and-effect relation.

The definition of a functional feature of the TFM in the form of $n$-ples has been introduced and elaborated by several authors; its historical aspects are discussed in more detail in [44]. It is important to know what knowledge and for what artefacts functional feature $n$-ple contains. The results of this analysis will be applied to the frame system to separate knowledge necessary to the TFM itself, and knowledge that can be used to infer some additional knowledge, e.g., necessary for generating software analytical diagrams, or for checking software functional requirements for incompleteness.

Analysing information in [37], [39], [45], [46], [33], it is clear that elements necessary for the TFM itself are A, R, O, PrCond, PostCond, S, Pr, Ex; and they will be presented in the suggested frame system. Other elements may be generated from these ones. Artefacts, i.e., analytical diagrams, use all the elements presented [7].

The bold font in element names indicates sets of elements as it is stated in definitions. Elements $\mathbf{O}$ (objects) and $\mathbf{R}$ (results) have quite informal definitions. It is not clear whether there must be one instance or several and in which cases. In order to clarify this, the following assumptions are made.

Object $\mathrm{O}$ has the responsibility to execute action $\mathrm{A}$ to get the outcome - result R. All considered sources indicate that there is a single object type that could also represent a set of objects (e.g., a collection that is to be considered a single type Collection $<$ Object $>$ ).

Result R of action A can be defined as "a thing that is caused or produced by something else; a consequence or outcome" [47], "expressed in client-valued terms" [48]. Therefore, in the frame system, the result can be represented by any type (as in the case of object $\mathrm{O}$, a set of objects should be considered a single type). This statement is not in contradiction with the assumption that the result can be an attribute of a class or another class made in [38].

Topological operation $\mathrm{Op}$ of class $\mathrm{Cl}$ (equals object $\mathrm{O}$ ) should be named as a union of names of action A and result $\mathrm{R}$. For example, in the case of functional feature "Calculating the maximum per year for sales", the topological operation of object collection Sales (or Collection $\langle$ Sale $\rangle$ ) will be Sales::calculateMaximumPerYear() and result $\mathrm{R}$ will be derived attribute Sales::/maximumPerYear of some numerical type.

Creating explicit assignments between frames of functional features and objects gives the possibility to look at the functionality of the system from the structural viewpoint, as well as to consider causal dependencies among objects from the functioning viewpoint.

A cause-and-effect relation is another element that requires deeper understanding. Identification of cause-and-effect relations is intuitive work based on a modeller's knowledge and understanding of system operation [49]. As stated in [32], "it is assumed in topological functioning modelling that a cause-and-effect relation between two functional features of the system exists if the appearance of one feature is caused by the appearance of the other feature without participation of any third (intermediary) feature." How to automate determination of cause-and-effect relations? Possible formalisation that will still require human participation is obligate determination and specification of all pre- and postconditions of every TFM functional feature [49]. Then it would be possible "to connect" a post-condition of one functional feature with an equal precondition (or part of it) of another functional feature. In such a way, a sequence of functional features would be defined. However, the question about logical (control) relations between such sequences within a behavioural scenario and among behavioural scenarios requires human participation in determining logical combinations of conditions.

\section{Frame Classes for Topological Functioning Model}

The frame system suggested here is based on (but not limited to) the elements necessary to generate the TFM without logical operations among cause-and-effect relationships. It represents domain ontology but does not specify scripts or daemons for frame instance generation. The following frame classes are developed (Fig. 2):

- CauseAndEffectRelation - for knowledge on causeand-effect relations completely generated from instances of frame FunctionalFeature;

- FunctionalFeature - for facts about the functional features, manually filled in;

- Object - for objects that participate in the functional feature execution, partially generated;

- Property - for domain object properties, manually filled in;

- TopologicalOperation - for knowledge about the operations that will implement actions of the functional features; the instances of this frame class are to be completely generated based on the values of frame FunctionalFeature values;

- TopologicalCycle - for holding facts about functional feature participation in cycles of functionality, partially generated.

Each frame class is identified by its name; it contains slots, fillers and facets. Now, frame classes hold only static knowledge on the domain, i.e., ontology. Further, integration with the product (business) rules must be implemented.

There are several frame classes whose slot values must be set and updated automatically. The first one is CauseAndEffectRelation, whose slot values are generated based on the facts that the cause is predefined by using a precondition, while the effect is specified by using a postcondition [38]. Thus, the frame instance is created and filled in when there is a case of the equal precondition and a postcondition.

The second one is frame TopologicalOperation, where the name must be set as a union of values of slots action and result of FunctionalFeature. The slot owner gets its value based on the value of slot object in FunctionalFeature frame, but the slot returnType by a type of the value of slot result. 


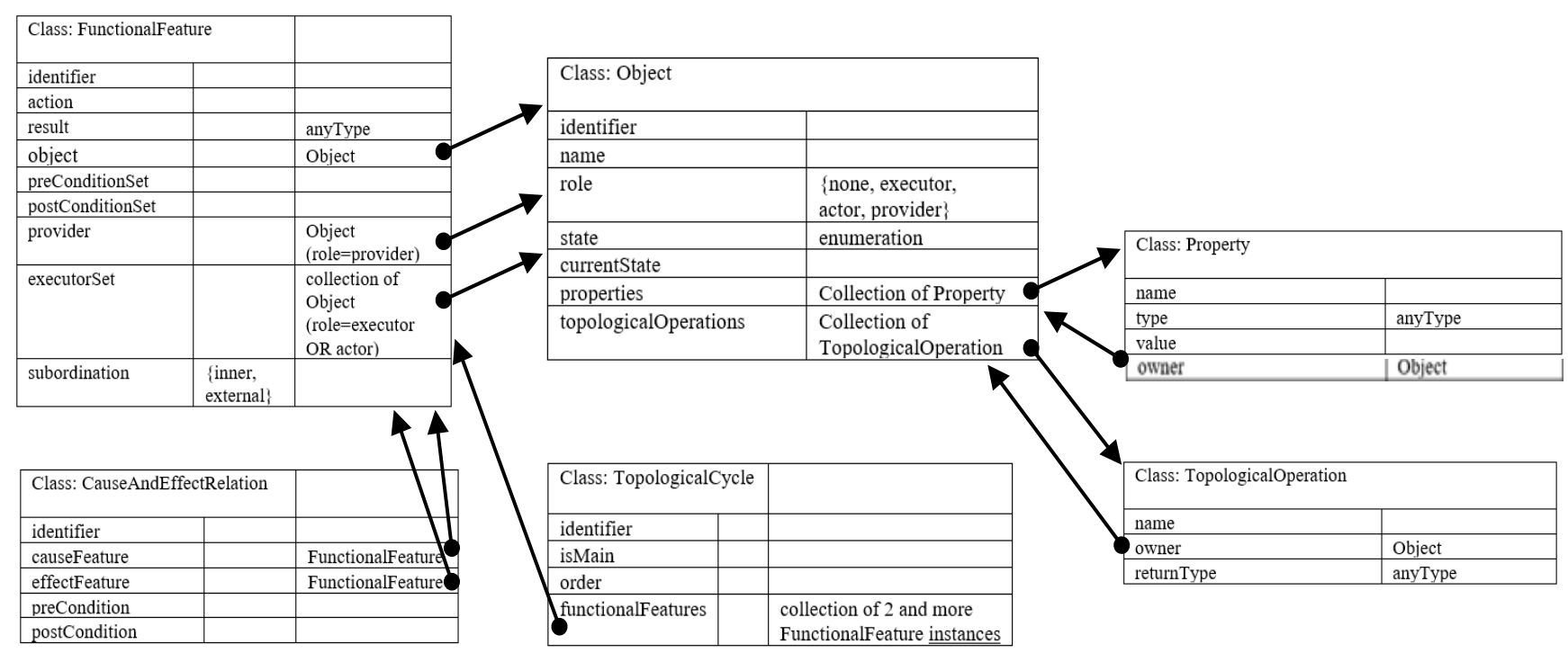

Fig. 2. The schema of the frame system.

Frames whose slot values are partially generated are Object (the value of slot topologicalOperation), and TopologicalCycle (the value of slot functionalFeatures). The latter is possible since in all the metamodels the topological cycle is represented as a set of functional features that are involved in some closed path.

Identifiers in all frames are also to be automatically generated.

\section{DEMONSTRATION ON THE EXAMPLE}

Description of the business domain is as follows. "A criminal case is initiated by an investigator when a criminal act is stated. The criminal act may be stated when a criminal person has committed a criminal act and it has been discovered or a victim or witness has submitted a claim about it. After the criminal case is initiated, the investigator conducts investigative actions. As a result, the indicted person is found. After the investigation is completed, the criminal case is sent to a prosecutor. If the criminal act is misdemeanour, the prosecutor can draw up a penal order. If the indicted person agrees with the accusation presented and the penalty the prosecutor offered, then the criminal case is terminated and the convicted person serves the punishment. Otherwise, the prosecutor sends the case to the court. The criminal case is terminated when the court adjudicates in the case. The Chief of Department assigns an investigator to a stated criminal act, and then the investigator initiates a new criminal case. The decision is based on the availability of investigators, since each investigator informs the Chief when the criminal case is sent to the prosecutor."

Having knowledge about the system, a modeller can fill in frame instances for functional features and objects with properties (Table I, Table II, Table V). Other frame instances are generated (Table III, Table IV, Table VI) and if necessary than filled in with not evident knowledge. The corresponding generated topological space of the system functional features is shown in Fig. 3. The topological space is valid, it contains no isolated vertices, has inputs, outputs, and a cycle structure.

The next step is to indicate system inner functional features. Let us imagine that we need to generate the TFM of the investigator work.

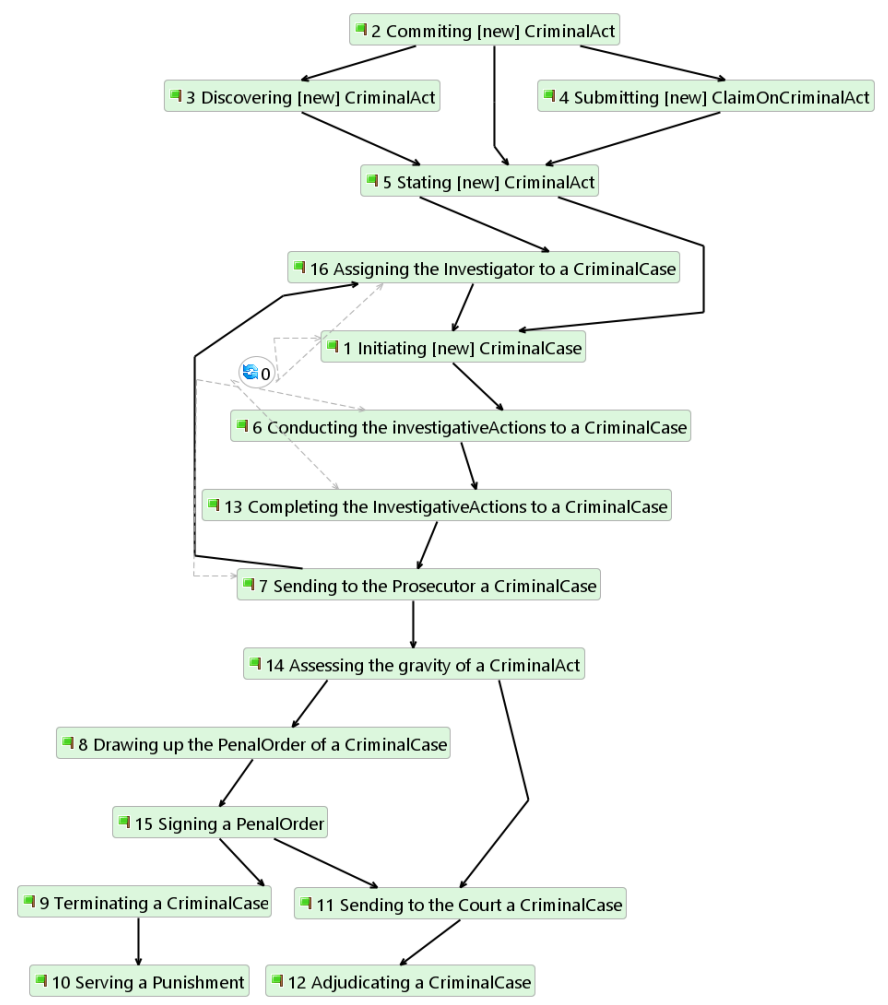

Fig. 3. The topological space obtained from the facts in the frame system.

Then the inner functional features are 1, 6, 7, and 13. The value of slot "subordination" of frame instances of them should be set to "inner" before closuring. After the closuring, the corresponding TFM is obtained (Fig. 4). 
TABLE I

FRAME INSTANCES FOR FUNCTIONALFEATURES [7]

\begin{tabular}{|c|c|c|c|c|c|c|c|}
\hline $\begin{array}{l}\text { Iden- } \\
\text { tifier }\end{array}$ & Action & Result & Object & preConditionSet & postConditionSet & Provider & executorSet \\
\hline 1. & Initiating & [new] & CriminalCase & $\begin{array}{l}\text { A criminal act is stated AND } \\
\text { an investigator is assigned }\end{array}$ & $\begin{array}{l}\text { A criminal case is } \\
\text { initiated }\end{array}$ & State Police & Investigator \\
\hline 2. & Committing & [new] & CriminalAct & & $\begin{array}{l}\text { A criminal act is } \\
\text { committed }\end{array}$ & & $\begin{array}{l}\text { Criminal- } \\
\text { Person }\end{array}$ \\
\hline 3. & Discovering & [new] & CriminalAct & A criminal act is committed & $\begin{array}{l}\text { A criminal act is } \\
\text { discovered }\end{array}$ & State Police & \\
\hline 4. & Submitting & [new] & $\begin{array}{l}\text { ClaimOn- } \\
\text { CriminalAct }\end{array}$ & A criminal act is committed & $\begin{array}{l}\text { A claim about a criminal } \\
\text { act is submitted }\end{array}$ & State Police & $\begin{array}{l}\text { Victim, } \\
\text { witness }\end{array}$ \\
\hline 5. & Stating & [new] & CriminalAct & $\begin{array}{l}\text { A criminal act is committed } \\
\text { AND (a criminal act is } \\
\text { discovered OR a claim about } \\
\text { a criminal act is submitted) }\end{array}$ & A criminal act is stated & & \\
\hline 6. & Conducting & $\begin{array}{l}\text { inves- } \\
\text { tigativeActions }\end{array}$ & CriminalCase & A criminal case is initiated & $\begin{array}{l}\text { An indicted person is } \\
\text { found }\end{array}$ & State Police & \\
\hline 7. & Sending & (to) Prosecutor & CriminalCase & $\begin{array}{l}\text { An investigation is } \\
\text { completed }\end{array}$ & $\begin{array}{l}\text { A criminal case is sent to } \\
\text { prosecutor }\end{array}$ & State Police & Investigator \\
\hline 8. & Drawing up & penalOrder & CriminalCase & $\begin{array}{l}\text { A criminal act is } \\
\text { misdemeanour OR a criminal } \\
\text { act is average gravity }\end{array}$ & A penal order is drawn & $\begin{array}{l}\text { Prosecution } \\
\text { Office }\end{array}$ & Prosecutor \\
\hline 9. & Terminating & & CriminalCase & $\begin{array}{l}\text { An indicted person agrees } \\
\text { with the penal order }\end{array}$ & $\begin{array}{l}\text { A criminal case is } \\
\text { terminated }\end{array}$ & $\begin{array}{l}\text { Prosecution } \\
\text { Office }\end{array}$ & Prosecutor \\
\hline 10. & Serving & & Punishment & A criminal case is terminated & & $\begin{array}{l}\text { Prisons } \\
\text { Administration }\end{array}$ & $\begin{array}{l}\text { Convicted- } \\
\text { Person }\end{array}$ \\
\hline 11. & Sending & (to) Court & CriminalCase & $\begin{array}{l}\text { NOT (an indicted person } \\
\text { agrees with the penal order) } \\
\text { OR a criminal act is grave }\end{array}$ & $\begin{array}{l}\text { NOT (a criminal case is } \\
\text { terminated) AND a } \\
\text { criminal case is sent to } \\
\text { the court }\end{array}$ & $\begin{array}{l}\text { Prosecution } \\
\text { Office }\end{array}$ & Prosecutor \\
\hline 12. & Adjudicating & & CriminalCase & $\begin{array}{l}\text { NOT (a criminal case is } \\
\text { terminated) AND a criminal } \\
\text { case is sent to the court }\end{array}$ & $\begin{array}{l}\text { A criminal case is } \\
\text { terminated }\end{array}$ & Court & \\
\hline 13. & Completing & $\begin{array}{l}\text { inves- } \\
\text { tigativeActions }\end{array}$ & CriminalCase & An indicted person is found & $\begin{array}{l}\text { An investigation is } \\
\text { completed }\end{array}$ & State Police & Investigator \\
\hline 14. & Assessing & gravity & CriminalAct & $\begin{array}{l}\text { A criminal case is sent to a } \\
\text { prosecutor }\end{array}$ & $\begin{array}{l}\text { A criminal act is } \\
\text { misdemeanour OR a } \\
\text { criminal act is average } \\
\text { gravity OR a criminal act } \\
\text { is grave }\end{array}$ & $\begin{array}{l}\text { Prosecution } \\
\text { Office }\end{array}$ & Prosecutor \\
\hline 15. & Signing & & PenalOrder & A penal order is drawn & $\begin{array}{l}\text { An indicted person agrees } \\
\text { with the penal order OR } \\
\text { NOT (an indicted person } \\
\text { agrees with the penal } \\
\text { order) }\end{array}$ & $\begin{array}{l}\text { Prosecution } \\
\text { Office }\end{array}$ & $\begin{array}{l}\text { Indicted- } \\
\text { Person }\end{array}$ \\
\hline 16. & Assigning & Investigator (to) & CriminalCase & $\begin{array}{l}\text { A criminal case is sent to a } \\
\text { prosecutor or a criminal act is } \\
\text { stated }\end{array}$ & $\begin{array}{l}\text { An investigator is } \\
\text { assigned }\end{array}$ & State Police & $\begin{array}{l}\text { Chef of } \\
\text { Department }\end{array}$ \\
\hline
\end{tabular}


TABLE II

FRAME INSTANCES FOR OBJECT [7]

\begin{tabular}{|c|c|c|c|c|c|c|}
\hline $\begin{array}{l}\text { Ident } \\
\text { ifier }\end{array}$ & Name & Role & State & $\begin{array}{l}\text { Current } \\
\text { state }\end{array}$ & Properties & topologicalOperations \\
\hline 1 & CriminalCase & none & isInitiated, isTerminated & & & $\begin{array}{l}\text { initiateNew(); conductInvestigativeActions(); } \\
\text { sendToProsecutor(); drawUpPenalOrder(); } \\
\text { terminate(); sendToCourt(); adjudicate(); } \\
\text { assignInvestigator() }\end{array}$ \\
\hline 2 & Investigator & executor/actor & & & & \\
\hline 3 & CriminalAct & none & $\begin{array}{l}\text { isStated, isCommitted, } \\
\text { isMisdeeanour }\end{array}$ & & gravity & $\begin{array}{l}\operatorname{commitNew}() ; \operatorname{discoverNew}() ; \operatorname{stateNew}() ; \\
\text { assessGravity() }\end{array}$ \\
\hline 4 & CriminalPerson & executor/actor & & & & \\
\hline 5 & ClaimOnCriminalAct & none & isSubmitted & & & submitNew() \\
\hline 6 & InvestigativeActions & none & & & & \\
\hline 7 & Investigation & none & isCompleted & & & \\
\hline 8 & Prosecutor & executor/actor & & & & \\
\hline 9 & Victim & executor/actor & & & & \\
\hline 10 & Witness & executor/actor & & & & \\
\hline 11 & IndictedPerson & none & & & & \\
\hline 12 & PenalOrder & none & isDrawn, isSigned & & $\begin{array}{l}\text { accusation, } \\
\text { penalty }\end{array}$ & signAgreement() \\
\hline 13 & Accusation & & isPresented & & & \\
\hline 14 & Penalty & & isOffered & & & \\
\hline 15 & Punishment & none & & & & serve() \\
\hline 16 & ConvictedPerson & executor/actor & & & & \\
\hline 17 & Court & none & & & & \\
\hline 18 & ChefOfDepartment & executor/actor & & & & \\
\hline
\end{tabular}

TABLE III

FRAME INSTANCES FOR TOPOLOGICALOPERATION

\begin{tabular}{|c|c|c|c|}
\hline Identifier & Name & Owner & returnType \\
\hline initiateNew & initiateNew & CriminalCase & CriminalCase \\
\hline conductInvestigativeActions & conductInvestigativeActions & CriminalCase & InvestigativeActions \\
\hline sendToProsecutor & sendToProsecutor & CriminalCase & Prosecutor \\
\hline drawUpPenalOrder & drawUpPenalOrder & CriminalCase & PenalOrder \\
\hline terminate & terminate & CriminalCase & \\
\hline sendToCourt & sendToCourt & CriminalCase & Court \\
\hline adjudicate & adjudicate & CriminalCase & \\
\hline assignInvestigator & assignInvestigator & CriminalCase & Investigator \\
\hline commitNew & commitNew & CriminalAct & CriminalAct \\
\hline discoverNew & discoverNew & CriminalAct & CriminalAct \\
\hline stateNew & stateNew & CriminalAct & CriminalAct \\
\hline assessGravity & assessGravity & CriminalAct & CriminalAct \\
\hline submitNew & submitNew & ClaimOnCriminalAct & ClaimOnCriminalAct \\
\hline signAgreement & signAgreement & PenalOrder & PenalOrder \\
\hline serve & serve & Punishment & \\
\hline
\end{tabular}


TABLE IV

FRAME INSTANCES FOR CAUSEANDEFFECTRELATION

\begin{tabular}{|c|c|c|c|c|}
\hline Identifier & $\begin{array}{l}\text { Cause- } \\
\text { feature }\end{array}$ & $\begin{array}{l}\text { Effect- } \\
\text { feature }\end{array}$ & postCondition (of the causeFeature) & preCondition (of the effectFeature) \\
\hline $2-3$ & 2 & 3 & A criminal act is committed & A criminal act is committed \\
\hline $2-4$ & 2 & 4 & A criminal act is committed & A criminal act is committed \\
\hline $2-5$ & 2 & 5 & A criminal act is committed & $\begin{array}{l}\text { A criminal act is committed AND (a criminal act is discovered } \\
\text { OR a claim about a criminal act is submitted) }\end{array}$ \\
\hline $3-5$ & 3 & 5 & A criminal act is discovered & $\begin{array}{l}\text { A criminal act is committed AND (a criminal act is discovered } \\
\text { OR a claim about a criminal act is submitted) }\end{array}$ \\
\hline $4-5$ & 4 & 5 & A claim about a criminal act is submitted & $\begin{array}{l}\text { A criminal act is committed AND (a criminal act is discovered } \\
\text { OR a claim about a criminal act is submitted) }\end{array}$ \\
\hline $5-1$ & 5 & 1 & A criminal act is stated & A criminal act is stated AND an investigator is assigned \\
\hline $5-16$ & 5 & 16 & A criminal act is stated & A criminal case is sent to prosecutor OR a criminal act is stated \\
\hline $16-1$ & 16 & 1 & An investigator is assigned & A criminal act is stated AND an investigator is assigned \\
\hline $1-6$ & 1 & 6 & A criminal case is initiated & A criminal case is initiated \\
\hline 6-13 & 6 & 13 & An indicted person is found & An indicted person is found \\
\hline $13-7$ & 13 & 7 & An investigation is completed & An investigation is completed \\
\hline 7-16 & 7 & 16 & A criminal case is sent to prosecutor & A criminal case is sent to prosecutor OR a criminal act is stated \\
\hline 7-14 & 7 & 14 & A criminal case is sent to prosecutor & A criminal case is sent to prosecutor \\
\hline 14-8 & 14 & 8 & $\begin{array}{l}\text { A criminal act is misdemeanour OR a criminal act is } \\
\text { average gravity OR a criminal act is grave }\end{array}$ & $\begin{array}{l}\text { A criminal act is misdemeanour } \mathrm{OR} \text { a criminal act is average } \\
\text { gravity }\end{array}$ \\
\hline $14-11$ & 14 & 11 & $\begin{array}{l}\text { A criminal act is misdemeanour OR a criminal act is } \\
\text { average gravity OR a criminal act is grave }\end{array}$ & $\begin{array}{l}\mathrm{NOT} \text { (an indicted person agrees with the penal order) OR a } \\
\text { criminal act is grave }\end{array}$ \\
\hline $8-15$ & 8 & 15 & A penal order is drawn & A penal order is drawn \\
\hline $15-11$ & 15 & 11 & $\begin{array}{l}\text { An indicted person agrees with the penal order OR } \\
\text { NOT(an indicted person agrees with the penal order) }\end{array}$ & $\begin{array}{l}\text { NOT(an indicted person agrees with the penal order) } \\
\text { criminal act is grave }\end{array}$ \\
\hline $15-9$ & 15 & 9 & $\begin{array}{l}\text { An indicted person agrees with the penal order OR } \\
\text { NOT(an indicted person agrees with the penal order) }\end{array}$ & An indicted person agrees with the penal order \\
\hline $9-10$ & 9 & 10 & A criminal case is terminated & A criminal case is terminated \\
\hline $11-12$ & 11 & 12 & $\begin{array}{l}\text { NOT (a criminal case is terminated) AND a criminal case } \\
\text { is sent to the court }\end{array}$ & $\begin{array}{l}\text { NOT (a criminal case is terminated) AND a criminal case is } \\
\text { sent to the court }\end{array}$ \\
\hline
\end{tabular}

TABLE V

FRAME INSTANCES FOR PROPERTY

\begin{tabular}{|l|l|l|l|}
\hline Name & Type & Value & Owner \\
\hline Gravity & $\begin{array}{l}\text { Enumeration } \\
\text { \{misdemeanour, } \\
\text { average, grave }\end{array}$ & misdemeanour & CriminalAct \\
\hline Accusation & Text & & PenalOrder \\
\hline Penalty & Text & & PenalOrder \\
\hline
\end{tabular}

TABLE VI

FRAME INSTANCES FOR TOPOLOGICALCYCLE

\begin{tabular}{|l|l|l|l|}
\hline Identifier & isMain & Order & functionalFeatures \\
\hline Cycle1 & True & 0 & $\{1,6,13,7,16\}$ \\
\hline
\end{tabular}

Though the model is small, it is valid, namely, it contains input (functional feature 5), output (functional feature 14), the functioning cycle (1-6-13-7-16-1), and has no isolated functional features. 


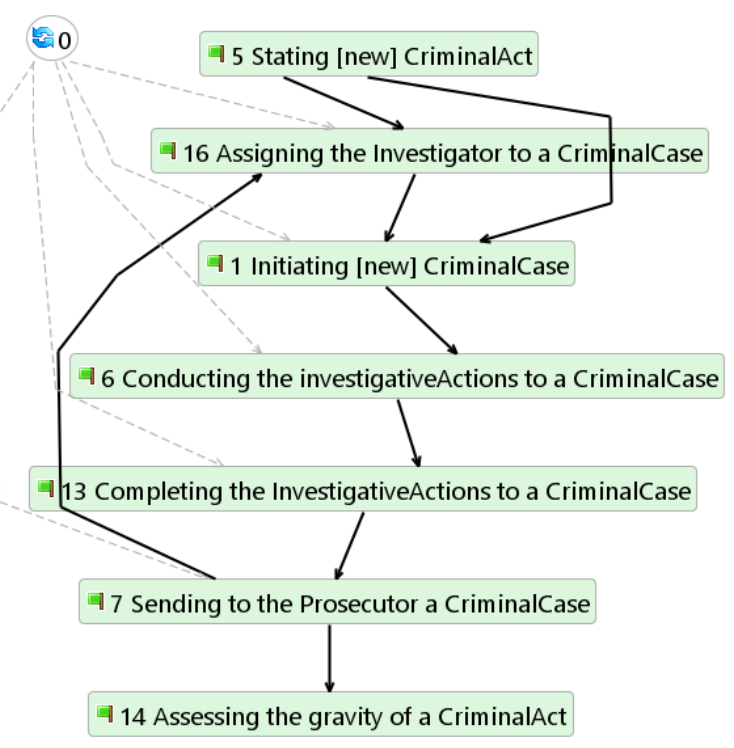

Fig. 4. The TFM obtained after closuring.

\section{CONCLUSION}

The knowledge frame system that represents the domain ontology can be applied for generation of the TFM. Some knowledge must be entered manually; the other can be filled in automatically using references to the corresponding frame class instances (facets). This structure is sufficient to generate TFM from it; however, logical operations on cause-and-effect relations are not presented, since the current version of the frame system does not hold the required constructs.

The decision of making a use of knowledge frames as a base knowledge representation format is grounded on its advantages such as uniqueness of names, implementation of closed world paradigm, semantic of constructs similar to the object-oriented paradigm, and default reasoning. Certainly, limitations mentioned in related work overview are also considered. They will affect the future refinement of the knowledge base, since nowadays it cannot be limited by frames only.

The knowledge system based on the principles of the TFM has such benefits: it does not allow inferring ambiguous statements, the structure of the frame system is similar to the object-oriented paradigm, principles that lie in the topological functioning modelling lead to more complete discovery of knowledge, and declarative and procedural knowledge from the frame system serves as the formal root view on the system at the very beginning of the development.

The defined difficulties in application are: definition of the proper client-valued result of the action and the corresponding object, handling business rules and logical operators on causeand-effect relations, use of proper inference engine, and integration with already existing ontologies that use an open world paradigm, thus allowing one to infer potentially untrue statements.

The future research is related to solving these difficulties and further elaboration of the frame system, while providing greater flexibility and maintainability.

\section{REFERENCES}

[1] J. Miller and J. Mukerji, "Model Driven Architecture (MDA)," 2001.

[2] OMG, "The MDA Foundation Model," SparxSystems, pp. 1-9, 2010.

[3] Y. Rhazali, Y. Hadi, and A. Mouloudi, "CIM to PIM Transformation in MDA: from Service-Oriented Business Models to Web-Based Design Models," Int. J. Softw. Eng. Its Appl., vol. 10, no. 4, pp. 125-142, 2016. https://doi.org/10.14257/ijseia.2016.10.4.13

[4] M. Kardoš and M. Drozdová, "Analytical method of CIM to PIM transformation in model driven architecture (MDA)," J. Inf. Organ. Sci., vol. 34 , no. 1 , pp. 89-99, 2010.

[5] I. Essebaa and S. Chantit, "Toward an automatic approach to get PIM level from CIM level using QVT rules," in 2016 11th International Conference on Intelligent Systems: Theories and Applications (SITA), 2016, pp. 1-6. https://doi.org/10.1109/sita.2016.7772271

[6] E. Asnina and J. Osis, "Topological Functioning Model as a CIMBusiness Model," in Model-Driven Domain Analysis and Software Development, Hershey, PA: IGI Global, 2011, pp. 40-64. https://doi.org/10.4018/978-1-61692-874-2.ch003

[7] V. Nazaruks and J. Osis, "Joint Usage of Frames and the Topological Functioning Model for Domain Knowledge Presentation and Analysis," in Proceedings of the 12th International Conference on Evaluation of Novel Approaches to Software Engineering (ENASE 2017), 2017, pp. 379-390. https://doi.org/10.5220/0006388903790390

[8] C. Roux, "Can 'Made Up' Languages Help Computers Translate Real Ones?," 2013

[9] A. A. Kornienko, A. V. Kornienko, O. B. Fofanov, and M. P. Chubik, "Knowledge in Artificial Intelligence Systems: Searching the Strategies for Application," Procedia - Soc. Behav. Sci., vol. 166, pp. 589-594, Jan. 2015. https://doi.org/10.1016/j.sbspro.2014.12.578

[10] M. Marinov, "Using XML to represent knowledge by frames," in Proceedings of the 5th international conference on Computer systems and technologies - CompSysTech '04, 2004, p. 1. https://doi.org/10.1145/1050330.1050350

[11] M. Minsky, “A Framework for Representing Knowledge,” 1974.

[12] H. H. Wang, N. Noy, A. Rector, M. Musen, T. Redmond, D. Rubin, S. Tu, T. Tudorache, N. Drummond, M. Horridge, and J. Seidenberg, "Frames and OWL Side by Side," in 9th International Protégé Conference, 2006.

[13] V. Nazaruks and J. Osis, "A Survey on Domain Knowledge Representation with Frames," in Proceedings of the 12th International Conference on Evaluation of Novel Approaches to Software Engineering (ENASE 2017), 2017, pp. 346-354. https://doi.org/10.5220/0006388303460354

[14] P. J. Beltrán-Ferruz, P. A. González-Calero, and P. Gervás, "Converting Mikrokosmos frames into description logics," Proceeedings of the Workshop on NLP and XML (NLPXML-2004): RDF/RDFS and OWL in Language Technology. Association for Computational Linguistics, USA, pp. 35-42, 2004. https://doi.org/10.3115/1621066.1621072

[15] W. Shiue, S.-T. Li, and K.-J. Chen, "A frame knowledge system for managing financial decision knowledge," Expert Syst. Appl., vol. 35, no. 3, pp. 1068-1079, Oct. 2008. https://doi.org/10.1016/j.eswa.2007.08.035

[16] A. T. Bimba, N. Idris, A. Al-Hunaiyyan, R. B. Mahmud, A. Abdelaziz, S. Khan, and V. Chang, "Towards knowledge modeling and manipulation technologies: A survey," Int. J. Inf. Manage., vol. 36, no. 6, pp. 857-871, Dec. 2016. https://doi.org/10.1016/j.ijinfomgt.2016.05.022

[17] L. T. Detwiler, J. L. V. Mejino, and J. F. Brinkley, "From frames to OWL2: Converting the Foundational Model of Anatomy," Artif. Intell. Med., vol. 69, pp. 12-21, May 2016. https://doi.org/10.1016/j.artmed.2016.04.003

[18] D. Grigorova and N. Nikolov, "Knowledge representation in systems with natural language interface," in Proceedings of the 2007 international conference on Computer systems and technologies CompSysTech '07, 2007, p. 1. https://doi.org/10.1145/1330598.1330670

[19] Y. Xue, H. H. Ghenniwa, and W. Shen, "A Frame-based Ontological view Specification Language," in The 14th International Conference on Computer Supported Cooperative Work in Design, 2010, pp. 228-233. https://doi.org/10.1109/cscwd.2010.5471972

[20] Y. Xue, H. H. Ghenniwa, and W. Shen, "Frame-based ontological view for semantic integration," J. Netw. Comput. Appl., vol. 35, no. 1, pp. 121-131, Jan. 2012. https://doi.org/10.1016/j.jnca.2011.02.010

[21] F. Corcoglioniti, M. Rospocher, and A. P. Aprosio, "A 2-phase framebased knowledge extraction framework," in Proceedings of the 31st 
Annual ACM Symposium on Applied Computing - SAC '16, 2016, pp. 354-361. https://doi.org/10.1145/2851613.2851845

[22] K. Kim, C. Lee, S. Jung, and G. G. Lee, "A frame-based probabilistic framework for spoken dialog management using dialog examples," in Proceedings of the 9th SIGdial Workshop on Discourse and Dialogue, 2008, pp. 120-127. https://doi.org/10.3115/1622064.1622088

[23] S. Kramer and H. Kaindl, "Coupling and cohesion metrics for knowledge-based systems using frames and rules," ACM Trans. Softw. Eng. Methodol., vol. 13, no. 3, pp. 332-358, Jul. 2004. https://doi.org/10.1145/1027092.1027094

[24] M. Marinov, "Using frames for knowledge representation in a CORBAbased distributed environment," Knowledge-Based Syst., vol. 21, no. 5, pp. 391-397, Jul. 2008. https://doi.org/10.1016/j.knosys.2008.02.003

[25] J. H. Gennari, P. Mork, and H. Li, "Knowledge transformations between frame systems and RDB systems," in Proceedings of the 3rd international conference on Knowledge capture - K-CAP '05, 2005, p. 197. https://doi.org/10.1145/1088622.1088666

[26] A. G. B. Tettamanzi, "A Fuzzy Frame-Based Knowledge Representation Formalism," in Di Gesú V., Masulli F., Petrosino A. (eds) Fuzzy Logic and Applications. WILF 2003. Lecture Notes in Computer Science, vol 2955, Springer Berlin Heidelberg, 2006, pp. 55-62. https://doi.org/10.1007/10983652_8

[27] A. Rector, "Axioms and templates: distinctions and transformations amongst ontologies, frames, and information models," in Proceedings of the seventh international conference on Knowledge capture - K-CAP '13, 2013, p. 73. https://doi.org/10.1145/2479832.2479840

[28] W. W. Sim and P. Brouse, "Towards an Ontology-based Persona-driven Requirements and Knowledge Engineering," Procedia Comput. Sci., vol. 36, pp. 314-321, 2014. https://doi.org/10.1016/j.procs.2014.09.099

[29] F. Al-Saqqar, J. Bentahar, and K. Sultan, "On the soundness, completeness and applicability of the logic of knowledge and communicative commitments in multi-agent systems," Expert Syst. Appl., vol. 43, pp. 223-236, Jan. 2016. https://doi.org/10.1016/j.eswa.2015.08.019

[30] I. Zeltmate, "Development of Intelligent System for Structural Modelling of Complex Systems," Riga Technical University, 2012.

[31] J. Z. Hernández and J. M. Serrano, "Knowledge-based models for emergency management systems," Expert Syst. Appl., vol. 20, no. 2, pp. 173-186, Feb. 2001. https://doi.org/10.1016/S0957-4174(00)00057-9

[32] J. Osis, "Topological Model of System Functioning," Autom. Comput. Sci. J. Acad. Siences, no. 6, pp. 44-50, 1969. (in Russian).

[33] J. Osis and E. Asnina, "Topological Modeling for Model-Driven Domain Analysis and Software Development: Functions and Architectures," in Model-Driven Domain Analysis and Software Development, Hershey, PA: IGI Global, 2011, pp. 15-39. https://doi.org/10.4018/978-1-61692-874-2.ch002

[34] E. Nazaruka, V. Ovchinnikova, G. Alksnis, and U. Sukovskis, "Verification of BPMN Model Functional Completeness by using the Topological Functioning Model," in Proceedings of the 11th International Conference on Evaluation of Novel Software Approaches to Software Engineering, 2016, pp. 349-358. https://doi.org/10.5220/0005930903490358

[35] V. Ovchinnikova and E. Nazaruka, "The Validation Possibility of Topological Functioning Model using the Cameo Simulation Toolkit," in Proceedings of the 11th International Conference on Evaluation of Novel Software Approaches to Software Engineering, 2016, pp. 327336. https://doi.org/10.5220/0005926003270336

[36] E. Asnina and V. Ovchinnikova, "Specification of decision-making and control flow branching in Topological Functioning Models of systems," in ENASE 2015 - Proceedings of the 10th International Conference on Evaluation of Novel Approaches to Software Engineering, 2015, pp. 364-373. https://doi.org/10.5220/0005479903640373

[37] J. Osis and E. Asnina, "Enterprise Modeling for Information System Development within MDA," in Proceedings of the 41st Annual Hawaii International Conference on System Sciences (HICSS 2008), 2008, pp. 490-490. https://doi.org/10.1109/HICSS.2008.150

[38] U. Donins, "Topological Unified Modeling Language: Development and Application," Riga Technical University, 2012.

[39] A. Slihte, "The Integrated Domain Modeling: an Approach \& Toolset for Acquiring a Topological Functioning Model," Riga Technical University, 2015

[40] E. Asnina, "Formalization of Problem Domain Modeling within Model Driven Architecture," Riga Technical University, 2006.
[41] J. Osis, E. Asnina, and A. Grave, "Formal computation independent model of the problem domain within the MDA," in CEUR Workshop Proceedings, 2007, vol. 252.

[42] J. Osis and U. Donins, "Platform Independent Model Development by Means of Topological Class Diagrams," in Model-Driven Architecture and Modeling Theory-Driven Development: Proceedings of the 2nd International Workshop on Model-Driven Architecture and Modeling Theory-Driven Development (MDA \& MTDD 2010), 2010, pp. 13-22.

[43] J. Osis, A. Slihte, and A. Jansone, "Using Use Cases for Domain Modeling," in Proceedings of the 7th International Conference on Evaluation of Novel Approaches to Software Engineering (ENASE 2012), Poland, Wroctaw, 29-30 June, 2012, pp. 224-231.

[44] A. Solomencevs, "Topological Functioning Model for Software Development within MDA (Survey)," in Proceedings of the 11th International Conference on Evaluation of Novel Approaches to Software Engineering (ENASE 2016), 2016, pp. 315-326. https://doi.org/10.5220/0005922803150326

[45] J. Osis and U. Donins, "Formalization of the UML Class Diagrams," in Evaluation of Novel Approaches to Software Engineering. 3rd and 4th International Conferences, ENASE 2008/2009, Funchal, Madeira, Portugal, May 4-7, 2008 / Milan, Italy, May 9-10, 2009. Revised Selected Papers, Springer Berlin Heidelberg, 2010, pp. 180-192. https://doi.org/10.1007/978-3-642-14819-4_13

[46] U. Donins, J. Osis, E. Asnina, and A. Jansone, "Using functional characteristics to analyze state changes of objects," in CEUR Workshop Proceedings. Databases and Information Systems. Tenth International Baltic Conference on Databases and Information Systems: Local Proceedings, Materials of Doctoral Consortium, 2012, vol. 924, pp. 94106.

[47] Oxford University Press, "Oxford Dictionaries," Oxford Dictionaries, 2013. [Online]. Available: https://en.oxforddictionaries.com/definition/result. [Accessed: 08-Jan2017].

[48] J. De Luca, "Feature Driven Development," Feature Driven Development Processes, 2002. [Online]. Available: http://www.featuredrivendevelopment.com/node/449. [Accessed: 08Jan-2017].

[49] E. Asnina, J. Osis, and A. Jansone, "System thinking for formal analysis of domain functioning in the computation independent model," in ENASE 2012 - Proceedings of the 7th International Conference on Evaluation of Novel Approaches to Software Engineering, 2012, pp. 232-240.

Vladislavs Nazaruks received a degree of Master of Engineering Science (Mg. sc. ing.) in computer systems in 2009 from Riga Technical University (RTU), Latvia.

He is a Researcher at the Department of Applied Computer Science, RTU. He also works as a Systems Analyst for ABC Software Ltd. Fields of his research interests: computer science, mathematics, pedagogy. Special interests: systems analysis and modelling, algorithms, information theory, protection of information.

Contact address: Department of Applied Computer Science, Riga Technical University, Sētas Str. 1, Riga, LV-1048, Latvia.

E-mail: Vladislavs.Nazaruks@rtu.lv 